\title{
Columbia's New Charging System
}

Miss Stubblefield is circulation librarian, and $\mathrm{Mr}$. Forrest, assistant circulation librarian, Columbia University Libraries.

$\mathrm{O}$ AUGUST I, I953, a new charging system was inaugurated in the Circulation Department of the Columbia University Libraries. The installation of the new method was the culmination of a long search by the circulation librarian to determine the means of giving the library clientele the maximum service. The search was made with the knowledge that controls should be designed to make materials available to readers in the most effective manner, and not, as some non-librarians believe, to frustrate the readers in their scholarly pursuits or to enrich the library by the collection of fines. As there is no perfect system which will be suitable to all libraries no matter what situations are peculiar to the individual institutions, a myriad of factors had to be considered.

From the preliminary investigations, several limiting factors were found which had to be considered by the circulation librarian in devising a new system; the major one being economy. The system should not be an expensive one. The total cost of the new circulation control could not exceed the present costs of equipment and personnel. It had to be one that could be used with the system of cataloging and preparation which had been used for the million books already in the stacks. The changeover had to be as simple as possible without the destruction of old records. It had to allow for the presence in the file of both old and new charges. Not only must it allow an easy changeover but also allow for a preliminary period of experimentation. In fact, such an experiment was made for four weeks in the Spring of 1952, during which period, time studies were made of routines and compared to those under the existing system. ${ }^{1}$

Other limiting factors involved the phys: ical features and set-up of the library. A seemingly minor matter such as the size of the pneumatic tubes had to be kept in mind. The location file, which was considered a permanent feature of the Circulation Department, had to be maintained. At Columbia the central circulation collection provides extra copies to all departmental libraries of books on reserve lists. It is estimated that approximately 20,000 to 30,000 items are loaned to departmental libraries on a long-term, but nevertheless, temporary basis-usually for a semester or more. For this reason, then, the charging system must serve as a location file as well as a current out file, for otherwise these books might be unavailable to the student for long periods of time as the card catalog would not indicate this temporary change of location.

These were the major limiting factors in devising a system. But why was a new system considered desirable? A brief exposition of the former routines helps to answer that question.

The Loan Desk at Columbia was divided into two sections, called the Delivery Desk and the Charging Station. At the former

1 Forrest, Fred H., "An Fxperiment in Charging in the Circulation Department, Columbia University Library." Unpublished Master's essay. Columbia University. School of Library Service, I952. 


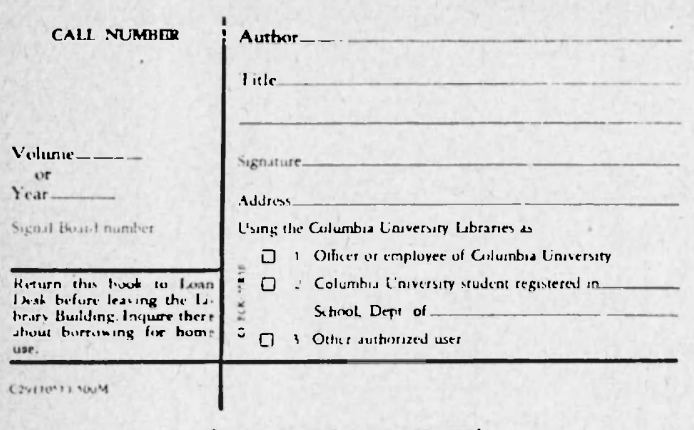

Fig. 1: Old Call Slip

the reader presented his call slip (Fig. I) and received his book. When the desk assistant delivered the book to the reader he placed in it a pre-dated and numbered transaction card and stamped with a Bates numbering machine the same number on the call slip. If the reader used the book in the library, he returned it to the same section; if he wished to take it home he went to the Charging Station where he signed his name and address on the permanent book card in the pocket of the book and where the attendant stamped the date due in the book. It was at this point that he returned the book when finished with it. At both Delivery Desk and Charging Station he was required to show identification as borrowing privileges are not extended to all users of the Columbia Libraries. After

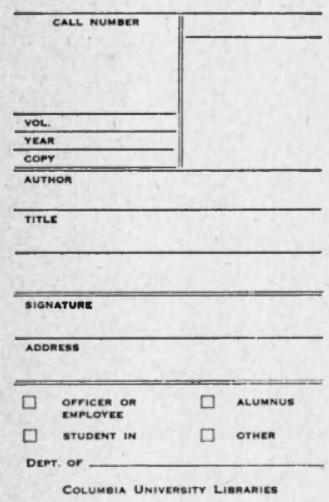

Fig. 2: Call SlipCharge Card

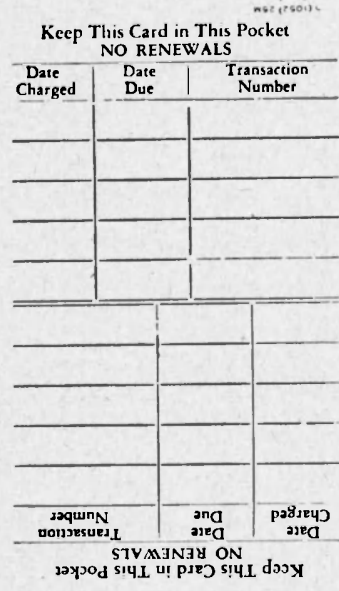

Fig. 4: Transaction Card

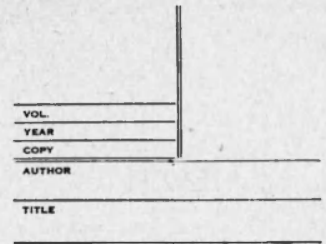

Fig. 3: Carbon Copy

the reader signed the book card it was dated and placed in the main location file, the only file maintained. Transaction cards were removed from books returned to the Delivery Desk and from the other books when they were charged for home use; at the end of the day the transaction cards were arranged by number and the call slips cancelled. Any uncancelled call slips represented books taken from the library without being properly charged. Books charged for home use were sorted when returned and slipped from the location file.

Certain disadvantages of such a system are immediately apparent if one looks at it from the reader's point of view:

(I) $\mathrm{He}$ must go to two separate places if he wishes to take a book out.

(2) He must sign name and address twice.

(3) $\mathrm{He}$ must show identification twice.

(4) He must distinguish between two return stations.

These were irritations which needed to be eliminated. At the same time, from a librarian's point of view there were two other much greater handicaps that prevented the reader from getting maximum service although he himself could not easily see them:

(I) At peak periods, such as after term papers were due and before examinations, books would be returned by the thousands. They piled up waiting to be slipped;-it might be two days before the book reached the shelf after being returned. This resulted in many reports of books being out when they were actually in the library.

(2) Daily or weekly sending of overdue notices was impossible. Notices were sent only at the close of each semester-three times 
a year. It was a slow, cumbersome process for an assistant had to handle card by card each of the approximately 60,000 entries in the location file to see if it represented overdue books. By the time the notice was sent, the student may have returned to California, India, or South America, and the chances of recovering the book greatly diminished.

In seeking for another system which would eliminate these weaknesses and at the same time stay within the imposed limitations, the circulation librarian considered several systems now in use at other libraries. None, however, would seem to fill all the requirements of the Columbia situation. Mechanical systems such as audio-charging ${ }^{2}$ or photographic charging ${ }^{3}$ would eliminate slipping and furnish a feasible overdue system, but they would involve considerable expense and would not allow for a location file. The Keysort method ${ }^{4}$ would allow for a location file, but it is considered most successful only when the file is relatively small because of the time involved in checking for overdues by use of the needle. To keep department and faculty charges (which are indefinite loans) in a separate file would require a large amount of time in checking location. Although a book card is not used in the Keysort method one must still have the book in hand in order to discharge it from the file. A fundamental drawback at Columbia was the size of the pneumatic tubes which would not allow the use of the Keysort or IBM cards. The cost of renting IBM machines as well as making master cards for over one million books would be prohibitive. Although this system is used in some public and university libraries $^{5}$ its use at Columbia was deemed

2 Smith, Stewart W., ". . and a Few Machines," Library Journal, 74:1044-47, July, I 949.

${ }^{3}$ Shaw, Ralph R., "Reducing the Cost of the Lending Process," A.L.A. Bulletin, 35:504-1 o, October I, I94I; Tucker, H. W., "Photographic Charging Machine," Library Journal, 71:1 779-83, December I 5, I946.

4 Stokes, Katharine M., and Chapin, Richard E., "On Using Keysort," Library Journal, 77:168-73, February

I, ${ }^{\text {I } 952 .}$ Quigley, Margery, "Library Facts from International impractical because it would not allow for a location file and would still make necessary the slipping of books if master cards were not made. For the latter reason the method of using tabs and similar arrangements for indicating due dates ${ }^{\text {i }}$ would not solve one of the major problems of the then existing system. In general these methods are considered more practical for small libraries. All of these considerations made it necessary to design a circulation control that, while resembling these several systems, is identical with none of them. Here, in brief, is how the system works:

The call slip, which also serves as the charge card, is a fold-over type of card with carbon on the back in order to make an impression on the fold-over portion. The face, or original (Fig. 2), carries the same information as the old call slip (Fig. I). It is the customary library size, $3 \times 5$, while the fold-over portion, or carbon copy (Fig. 3), is only $3 \times 3$, thereby eliminating from this portion the information about the library client. The reason for the size of the carbon copy is that the tube system at Columbia is quite small and will not take a regular library size card in a sufficiently heavy paper stock.

The reader fills out the call slip-charge card and presents it at the desk. The desk assistant, after the call number has been checked in the location file, tears the two portions of the card apart, keeps the original at the desk, and sends the carbon to the appropriate tier. When the book comes to the desk with the carbon copy in it, it is

\footnotetext{
Business Machine Cards," Library Journal, 66:1 065-67, December I5, I94I; Parker, Ralph R., "The Punched Card Method in Circulation Work," Library Journal, 6I:900-05. December I, 1936.

"Hood, Marjorie, and Lyle, Guy R., "A New System of Book Charging for College Libraries," Library Journal, 65:1 8-20, January I, I 940; Sister Helen, "Simplified Circulation Records for a College Library," Library Journal, 66:201-03, March I, I 94 I; Lynn, Lawrence C., "We Do It This Way," Catholic World, I2:I90-9I, March, I94I; Hamlin, A. T.. and Wright, W. W., "Garch, I94I; Hamlin, A. T.: and Wright, W. W., 20, December I, 1948 .
} 
matched with the original. The desk assistant takes a pre-dated transaction card (Fig. 4) showing date charged and date due and stamps on it in the space designated a transaction number by means of a Bates numbering machine. With the same machine set at "duplicate," he stamps the carbon copy with the same number. The transaction card is slipped into the book pocket and the charging operation is completed.

The original is stamped with the date of the operation and placed in a box for filing in the location file. The carbon copy is also dated and it is filed in a transaction file under the date by transaction number. At Columbia we have two charging desks, one at the Loan Desk and one at the stack exit. That means that for each day we have a separate series of transaction numbers for each date. In order to avoid any confusion in case of duplication a different color of ink pad is used in the Bates machine at the stack exit and a different colored pad is used when dating these charges.

As the charging operation is now completed at the Delivery Desk the former Charging Station is no longer needed for that purpose and has become instead the Return Desk. All books are returned at this point whether used in the library or taken home. Some books are non-circulating material and thus marked. The assistant at the Delivery Desk uses for these a transaction card on which only date charged is recorded. A slip reading "FOR USE IN THE LIBRARY" is placed in the book and it must be returned on the date borrowed. The same procedure is used for charges to persons who do not have borrowing privileges. The carbon copy is also marked making it easy to determine the next morning if all these charges have been returned. A charge to a departmental library or faculty member follows the same procedure except that no "FOR USE IN THE LIBRARY" slip is placed in the book. For the convenience of the desk assistant a transaction card of a different color is used for those on which only date charged is indicated.

When a book is returned at the Return Desk an assistant removes the transaction card from the pocket and places the book on a truck to be returned immediately to the shelf. The returned transaction cards are arranged by date and transaction number. From these cards the carbons in the transaction file bearing the same transaction numbers are removed. These cancelled carbons are then arranged by call number so that the originals may be pulled from the location file and the two parts destroyed. The charge cards of a day's charges are kept at the Return Desk throughout the day so that books used only in the library may be discharged before they are filed in the location file. The charge cards remaining at the end of the day represent the charges for home use and they are filed in the location file after they have been counted.

The carbon copies in the transaction file which remain for a certain date are the overdues (that is, excepting those charged to departments or faculty members). The original is pulled from the location file, the shelves are checked, and the overdue notice sent. It has been found that this type of card photographs well in the photo-clerk, although to date only third notices have been photographed. When scheduling difficulties of the photo-clerk are ironed out, the photographing of all overdues would undoubtedly be practicable.

During the four week experiment, a complete manual of procedure was drawn up. Slight improvements have been made in the procedure both during the experimental period and since the system was permanently established; however, no major changes 
have been made in the basic features of the system. Trial runs have been made on two types of call slips, interleaved and spot carbon. Spot carbon causes some smudging in the file but not to the extent of making any charges illegible, and it was found that spot carbon makes a better impression and eliminates the extra procedure of tearing out and disposing of the carbon. For these reasons, the spot carbon call slip is now being used.

It should be apparent that the limiting factors which were major considerations in the designing of the new system have been observed. This is not an expensive system. The only piece of machinery used is the Bates numbering machine which costs about eighteen dollars. The same card trays, guide cards, and overdue notices are used. The increased cost of the call slips is somewhat offset by the elimination of the book card and the time taken in preparation of the latter. The transaction card replaces the date due slip and the transaction cards formerly used at the Delivery Desk. No changes had to be made in the cataloging preparation for the books already in the collection. The new system is operated with the same circulation personnel as the old. Some routines have been added but old ones have been dropped: the new routine at the Delivery Desk is more complex but the Charging Desk is entirely eliminated; discharging from two files is compensated for by the elimination of the extra sorting and handling of the books in slipping under the old system. The changeover was easily made as old charges could be slipped as previously without interfering with the new discharging routine. A permanent feature of the Circulation Department, the location file, has been retained.

There are drawbacks as any system must have. Here are the most important ones that we have experienced in our first few months using this system:

(I) Some books which have been reserved by other readers are returned before they are due. These books go back to the shelves immediately as we do not know until the book is discharged from the location file that it is reserved. One must then go to the shelf for it and occasionally it has already been charged out by another reader. If we recall a book we request the reader to return the post card with the book. In that case the book is placed in a designated place so that it may be checked in the file for the reserve. We have found the readers willing to cooperate with us in this matter.

(2) Legibility is sometimes a problem as the readers fill out the call slip themselves in pencil. They are naturally not as easy to read as a typewritten book card would be. We do have the author and title on which to double check if the call number is not plain.

(3) This system requires very accurate work on the part of the desk assistants. Such accuracy in the matter of volume and copy numbers may be slighted in very busy periods when one is working under pressure. Lack of complete information can be cleared up by checking shelf list and shelves, but that is time consuming.

The test of the new system is whether it has eliminated the drawbacks of the old without generating proportionately greater ones. It should be obvious that this system has cleared up the sources of reader irritation:

( I) The reader now goes to only one point for the operation of charging a book. In the time studies it was found that the operation of giving a book to a reader under the old system averaged 13 seconds and the Charge Desk operation averaged 27 seconds, making a total of 40 seconds. Now that both operations are combined the time averages 22 seconds. A difference of 18 seconds may sound negligible but a reader may take several books at once, and these figures do not show the time wasted in waiting at another desk. From reader reaction we know that they appreciate this time saving.

(2) He signs his name and address only once. 
(3) He shows identification but once.

(4) $\mathrm{He}$ does not have to distinguish between two return points.

It should be remarked however that the above advantages apply only to the readers applying for books at the Loan Desk. Readers who have stack access must fill out the call slip; in the past they only signed name and address on the book card. Some, however, have already filled out the call slip when they consulted the catalog. Few have complained and those that have objected have been ready to cooperate when we have explained the two features of the new system that make books more readily available for the reader:

(I) Books are returned immediately to the shelf. Within four hours after their return they are on the shelf and available in contrast to 24 or 36 hours under the old system.

(2) Regular over-due notices have resulted in books being returned more promptly, making them available for other readers. There are already indications that book losses will be reduced.

There have been other minor advantages which have been of help to the department:

(I) All information is on the face of the card, making checking in the file easier. Under the old system one might have to pull the card from the file and turn it over if the signature was on the back. If photographed for overdues, two exposures were necessary for one card.

(2) Author and title are copied by the reader from the card catalog. Under the old system, desk assistants had to make new book cards when the old one was filled or the book had none. As the bibliographic background of staff members is somewhat limited, they could not always make them accurately, especially for languages such as Russian.

(3) It is now possible to make a check of faculty and departmental charges from the transaction file without going through the location file charge by charge.

(4) Retaining the original call slip at the Delivery Desk while the carbon copy is sent to the stacks has been of advantage to the desk assistant. He knows exactly what slips have been sent to the stacks and can check if there is any delay. If a carbon is lost by the page he has the call number and does not have to require the reader to go back to the catalog. $\mathrm{He}$ can be certain when a reader has received all the books for which he is waiting.

In evaluating any method of circulation control, the advantages and disadvantages must be carefully considered and weighed. The advantages both to readers and to departmental personnel must greatly outweigh the disadvantages. It would not be practical or sound for any library to install this charging system or any system without first considering its own particular problems. Any charging system must be unique ; that is, if transplanted to another library it must be changed in many aspects to suit the peculiar situations of that library. After eight months of use, this charging system now used at Columbia has proved to have sound basic principles which make for effective circulation control and which may be easily and effectively adapted to other libraries.

\section{Library Building Plans Institute}

Tentative plans for the Third Library Building Plans Institute sponsored by the ACRL Library Buildings Committee are being made. If sufficient interest is expressed, the Institute will be held on January 29 and 30 at the Morrison Hotel in Chicago as a preconference activity of the 1954 Midwinter Meeting of the American Library Association.

Librarians interested in presenting their plans for criticism or in attending the Institute are asked to write immediately to Charles M. Adams, chairman, ACRL Buildings Committee, librarian, Women's College, University of North Carolina, Greensboro. 